\title{
FINES DE LA EDUCACION EN EL FUTURO*
}

\section{Dr. Luis Enrique Orozco Silva**}

Hablar del porvenir de la escuela, aunque significa un gran riesgo, tiene la benevolencia de no obligarme a no hacer un análisis coyuntural de la realidad educativa o a hacer una serie de recomendaciones pragmáticas para el futuro. Tengo sí como telón de fondo la realidad de un sector social que se debate en graves problemas que hacen dudar de su eficacia ante las exigencias del cambio social requerido. Son ingentes los esfuerzos del gobierno por salvarlo del letargo en que se encuentra, y cada día vemos con más claridad que sin la solidaridad de todos los que de una $u$ otra forma tienen una responsabilidad en él será imposible salir adelante.

Enumeremos sólo algunos aspectos para enmarcar nuestra reflexión y darle un sentido de realidad, sin pretender con ello hacer un diagnóstico acabado.

Para todo observador del sector educativo sorprende cómo por medio del Decreto 3157 de 1968 se crearon los Fondos Educativos Regionales para evitar que los dineros destinados a la educación pública se desviaran hacia otros fines y hoy se convierten en una estructura administrativa y financiera paralela a las secretarias de Educación: La Nación paga los costos de la educación pero no puede imponer decisiones; los departamentos nombran sin los recursos adecuados. La doble estructura arriba mencionada, genera duplicidad de funciones, desaprovechamiento de recursos, colisión de competencias y desconocimiento de obligaciones hasta el punto que el desorden administrativo así engendrado repercute penosamente sobre las finanzas de la educación impidiendo hasta el cálculo del monto de la deuda a los educadores, reduciendo las funciones del MEN y distorsionándolas. El Ministerio tiene que administrar la educación y no puede planearla, evaluarla, inspeccionarla y vigilarla adecuadamente. El Estatuto Docente (Decreto 2277/79) tiene implicaciones financieras que no fueron estimadas suficientemente; la burocratización aqueja a todo el sector y lo hace inoperante. Todo ello está esperando un reordenamiento del sector que conlleve una descentralización de su administración, una claridad en la normatividad en materia de educación, una redefinición de los institutos adscritos al MEN, y una mejor adecuación entre lo que brinda la institución escolar y las necesidades del país.

Estas medidas, sin embargo, ayudarían a una mayor eficacia de la administración pero no ir(an muy lejos sin atender los problemas relativos a la calidad de la educación, a la capacitación del magisterio, a la reforma curricular, a la inserción de los recursos tecnológicos y de los medios masivos de comunicación a los procesos de enseñanzaaprendizaje, a la participación de la comunidad en las decisiones de la escuela.

En los últimos gobiernos se ha buscado ampliar la cobertura, mejorar el rendimiento interno del aparato educativo, todo lo cual se ve reflejado en el mejoramiento de la tasa de retención. De igual manera podríamos decir que el énfasis de los gobiernos ha estado en aumentar el volumen de los recursos para el sector, en hacerlos fluir automáticamente hacia él, en solucionar problemas de administración o del personal sin plantearse aquellos

\footnotetext{
* El texto reproduce la intervención oral del autor en mesa redonda, en la Biblioteca Luis-Ángel Arango. Bogotá, sept. 27 de 1984.

** Doctor en Filosofía y Letras de la Universidad Católica de Lovaina. Profesor de la Universidad de los Andes. Miembro de la Sociedad Colombiana de Epistemología.
} 
relacionados con una política educativa nacional coherente, o los que tienen que ver con los fines de la educación.

Este último problema es el que deseo plantear ante ustedes de manera muy breve para posibilitar la discusión. Pensar en los fines de la educación es parte fundamental de una política en materia educativa y ello no puede hacerse sin referirnos a las estructuras globales de la sociedad en que nos ha tocado vivir. Bien sabemos que la realidad de la escuela, las funciones que se le asignen y sus fines están en íntima relación con un determinado proyecto social, con un determinado estilo de desarrollo y ambos implican opciones ideológicas.

Recordemos el tiempo en que la aceptación acrítica de un modelo de desarrollo por parte de los teóricos de la educación los condujo a aceptar sin beneficio de inventario la concepción tradicional de la escuela y su función en la sociedad como institución educativa por excelencia que nos sacaría de la ignorancia y el subdesarrollo hasta llevarnos a un estadio de "ilustración" y "civilización". Pues bien, el tiempo ha pasado, las teorías sobre el desarrollo han evolucionado pero quizá, en nuestro medio, se siga pensando la escuela de manera aislada a la dinámica social.

Si miramos la escuela más allá de su concepción tradicional creemos que hacia el futuro debe ser algo más que un lugar de transmisión de conocimientos, de costumbres, de valores imperantes en una sociedad dada. Deberá ser un medio entre otros, un lugar entre otros en el cual quienes a él van aprenden a aprender, aprender a hacer y aprender a ser. Sólo de esta manera la escuela se abrirá a la vida y se constituirá en factor de cambio social.

Para que en la escuela se aprenda a aprender será necesario que no asociemos la institución escolar con unos programas, unos alumnos, unos métodos y un personal dedicado especialmente a la labor de enseñar. Como si la realidad de la escuela constituyera un mundo aparte, un paréntesis en la vida que cada quien trata de superar cuanto antes como signo de madurez intelectual y hasta moral. A esta idea viene asociada una segunda que le es afín: la educación suele ser entendida como un proceso de formación, delimitado en el tiempo, que nos prepara para la vida. Período que cubre nuestra niñez, adolescencia y juventud y a cuyo término ingresamos a la sociedad civil para desempeñar funciones y adquirir responsabilidades. No se estará pensando que en el fondo nuestra existencia se divide en dos grandes etapas: aquella en que nos educamos; en la cual hasta se nos permite una cierta dosis de irresponsabilidad y aquella en que somos útiles a la sociedad en la cual se nos permitiría pensar que no necesitamos volver a estudiar?

¿Por qué no pensar que no hay edad para la educación, que esta es una dimensión de la vida, que es un proceso permanente y continuo. Por qué no convencer a los jóvenes de que la escuela los prepara para seguir aprendiendo, por qué no modificar las nociones de tiempo y espacio de la educación de modo que esta no se circunscriba a la escuela únicamente, que esta no detente el monopolio de la educación? Aprender a aprender puede ser más importante que la "alegría de enseñar". ¿Por qué no pensar en hacer menos rígidos los sistemas educativos en relación con la forma como están integrados, por qué no evitar el carácter totalizador del curriculum, por qué no favorecer la educación permanente?

Para que cobre significación en la escuela "el hacer", la práctica, será necesario que hacia el futuro vinculemos educación y trabajo, no sólo en el sentido de incorporar a la escuela la experiencia del trabajo productivo, cuya viabilidad deberá ser estudiada y 
evaluada cuidadosamente, aunque en países como Asia y África haya tenido un éxito relativo, sino en el sentido de liberar al niño y al adolescente del sentimiento de irrealidad que se deriva del conflicto entre una cultura libresca y a veces importada y las exigencias de la vida cotidiana. Por qué no pensar que la escuela debe abordar los problemas de la vida real, transformar la experiencia en conocimientos, explicar las condiciones de aparición del presente?

Para ello como lo señala Schwarts - cuya posición asumo en este punto- - será necesario colocar a los alumnos individual y colectivamente en condiciones de analizar ellos mismos su práctica, de detectar en ella "sus" teorías y medir personalmente las disparidades entre las teorías y lo que propone la escuela. En otras palabras, será necesario que cobremos conciencia de la importancia de distinguir la lógica de la transmisión de conocimientos (lógica de la escuela), de la lógica de la producciónrealización y de la lógica de la investigación. No olvidemos que saber no es más que un modo de asumir lo imprevisto en la producción y reproducción de nuestra propia existencia como especie y como individuos.

La finalidad última de la educación es tan conocida como desatendida en la práctica de la educación: aprender a ser. Ello significa, como lo señala Legrand que todo acto educativo "ya se trate de un estudio, un ejercicio o una práctica es una modificación del ser en el conjunto de sus dimensiones. El ser en sí mismo de algún modo se convierte en el contenido de su propia educación. Este contenido, esta materia prima va tomando forma a través de una actividad educativa y adquiere las capacidades y competencias que únicamente existían en el individuo de una manera virtual". En este proceso, el educador es sólo una mediación tanto más creativa cuanto menos domesticadora, tanto más rica y excitante cuanto más sea expresión y testimonio de una experiencia vivida por parte del maestro.

La reflexión sobre los fines de la educación nos conduce a preguntarnos por la naturaleza de la práctica pedagógica. Hacia el futuro es necesario trascender la idea según la cual aquella consiste en una acción instrumental; es decir, en una acción regida por un criterio único: el logro de objetivos fijados de antemano, orientada por reglas independientes del contexto social "reglas técnicas", de carácter condicional y en la cual la sanción consiste en el logro o no de un resultado. Así entendido el trabajo del maestro, el éxito de su tarea estaría en la correcta selección de medios y su finalidad sería la eficacia y la productividad. Pero si a ello se reduce la acción pedagógica sobraría la pregunta por los fines de la educación, se aceptaría sin beneficio de inventario que sus fines se definen desde el exterior de ella misma, en las exigencias del modelo o estilo de desarrollo vigente. Por el contrario, postulamos que la acción pedagógica es una interacción y en cuanto tal es antes que todo un proceso de comunicación que se inscribe en pautas culturalmente prefiguradas, que se orienta por normas sociales ligadas al desarrollo histórico de las instituciones, que implica una normatividad no condicional que se transmite e internaliza de manera, muchas veces tácita, y cuya trasgresión origina un sentimiento de culpa. Conlleva, en consecuencia, una dimensión simbólica, crítica e histórica que la convierte en mediación para que a través de ella el estudiante y el maestro sea cada quien él mismo en la conciencia de su diferencia mutua. La interacción educativa conlleva una dialéctica del reconocimiento, un acuerdo siempre incompleto sobre su finalidad y una conciencia mínima del proceso mismo. Lo que está en juego en ella es el hombre como proyecto histórico que se fragua en un mar de determinaciones finitas, para cuya trascendencia la educación es un medio. Sólo así podremos hablar de una educación para la libertad y para la eticidad. Sólo de esta manera la educación se convertirá en factor de cambio social posibilitando que mediante una autoconciencia 
colectiva la sociedad futura posea estructuras menos ofensivas para la esencial dignidad del hombre colombiano.

Pero, qué significa educar para la libertad y la eticidad? Se trata, en afecto, de acentuar como finalidad de la acción educativa el desarrollar en la persona del educando una conciencia moral, una capacidad de emitir un juicio ético sobre la sociedad en que vive. De esta manera, la escuela asume no sólo una responsabilidad ante el saber y frente a la inteligencia del joven, sino una posición ético-política frente a la comunidad de la cual forma parte. ¿Cómo vincular libertad y eticidad como fines de la educación? Veámoslo de manera muy esquemática.

Aceptemos como punto de partida que la relación y el orden que se da entre los sucesos en el sistema de la naturaleza deben ser encontrados, o por lo menos buscados, en la naturaleza; de tal manera que frente a tal orden y relación -que expresan la necesidad natural- la libertad por una parte nos libera de la necesidad y de otra del beneficio de tal guía. Así las cosas, podemos decir que la libertad se presenta como liberación de la necesidad natural. Como lo dice Kant naturaleza y libertad se contraponen como legalidad o ilegalidad; la primera obliga al entendimiento a buscar la procedencia de los sucesos en el marco de la causalidad natural y premia también su logro al hacer explícito a través de dicho esfuerzo una unidad universal y legal de la experiencia. La libertad en cambio aunque deja al entendimiento en reposo busca en la cadena de las causas hasta llegar a una causalidad incondicionada que trasciende las reglas, que obra desde sí misma, que hace posible una experiencia totalmente coherente.

Naturalmente, ello implica que aceptemos que el entendimiento tiene un limite más allá del cual la razón puede como "Facultad de lo absoluto,,, como capacidad de pensar lo incondicionado; como propiedad exclusiva del hombre, representarse leyes universales, válidas para todo ser racional y a cuya luz puede ser determinada toda acción singular. Debemos entender que cada uno de nosotros, en el contexto del universo, no es pensable sino como libertad; es decir, como capacidad de evadir los determinismos de la naturaleza. Cada uno de nosotros no solo conoce las leyes objetivas que rigen el mundo natural sino que puede oponerse a la naturaleza. En la autoconciencia se construyen esas dos realidades opuestas: la conciencia del yo y la objetividad.

Este planteamiento sobre la libertad se prolonga, en la obra de Kant, sobre el plano de la moral. En efecto, al preguntarse por la posibilidad de la autonomía del individuo, considera que ésta sólo puede darse si el sujeto puede constituir a partir de si mismo una objetividad propia, universal; de esta manera excluye toda heteronomía en la fundamentación de la moral (ni Dios, ni leyes, ni el amor...). La acción tiene su fundamento en el mismo sujeto que obra; "la ley moral es una ley de causalidad en libertad" como pretensión de universalidad: "obra como si la máxima de tu acción debiera tomarse como ley universal de la naturaleza". Pero, podríamos preguntarnos: ¿Cómo elevar su contenido particular a ley universal? ¿Cuál sería el criterio de tal operación?, ¿Si excluimos la recurrencia a la forma de la ley, por ser ésta precisamente sólo forma sin contenido? Kant terio en la ausencia de contradicción al tratar de hacer dicha conversión encuentra ese criterio en la ausencia de contradicción al tratar de hacer dicha conversión y lo ilustra con un ejemplo. Tomo como máxima de mi acción aumentar mi fortuna por todos los medios posibles. Ahora bien, tengo en mi poder un depósito de alguien que ha muerto sin haber dejado constancia ni prueba alguna del depósito confiado, y me pregunto, si al hacerlo propio puedo convertir aquella máxima en ley universal. Es decir, si todos pueden apoderarse del depósito que se les confíe. 
Si ello fuere así sería imposible toda legislación, puesto que produciría, por el contrario, la más grave contradicción y la destrucción de la máxima y de su intención. Si así fueran las cosas, nadie daría un depósito y por lo tanto no habría ni máxima ni ley. Luego, la máxima que sí puede convertirse en ley universal sería: no debo apoderarme de ningún depósito que me haya sido confiado.

Podemos señalar tres características básicas de estos planteamientos de Kant para los fines que nos interesan, a) La razón es la única legisladora. Todo ha de derivarse de ella y no de algo dado, de ningún hecho, o de la experiencia, o de alguna ley o costumbre. b) El sujeto debe hacer coincidir su máxima con la forma universal de la ley para que ésta pueda tener algún contenido, e) El rechazo de lo dado permite la constitución de un mundo de moralidad adecuado a la voluntad del sujeto legislador.

Esquematizando, podemos decir que Kant nos permite pensar la libertad singular, subjetiva, aquella del individuo aislado. Más aún, que funda el mundo de la moralidad en el interior de la persona singular. Más de uno encuentra en este planteamiento satisfacción y seguridad para afianzar su individualismo,

Debemos reconocer, no obstante, que la libertad subjetiva, no es toda la libertad; más aún, que no podemos reducir la libertad al libre arbitrio, vaciándola de contenido y colocándola en el plano del debe ser. La modalidad subjetiva no se da sino en el plano de la eticidad. Esta última es la esfera objetiva en la que se realiza la libertad del individuo, y está constituida por la totalidad de las relaciones humanas, por las instituciones que encarnan y materializan la libertad. Instituciones y relaciones que al ser reconocidas por los individuos como medio de realización efectiva de su libertad, se colocan como finalidad y principio de su acción. Moralidad y eticidad son, pues, dos momentos distintos y complementarios de la libertad efectiva. La libertad de cada quien no se ejerce sino en el interior de relaciones entre el medio existente (derecho, costumbres, instituciones...) y el sujeto singular. Un Estado real es aquel en el que unidos moralidad y eticidad genera las condiciones de una libertad colectiva en el interior de las cuales el individuo encuentra su liberación en el deber. La eticidad se articula en lo social y lo político; sólo en el interior de un orden político racional la libertad deja de ser una ficción, o el privilegio de unos pocos, para convertirse en responsabilidad de todos.

La libertad debe ser pensada desde la eticidad, mediada por la historia de los grupos humanos.

Desde esta perspectiva, educar para libertad no es posible sin plantearse el problema de la eticidad, el problema de la historia, de las instituciones políticas. La acción educativa no puede evadir su responsabilidad como conformadora de la conciencia moral y ética de sus educandos, Esta responsabilidad ético-política es insoslayable. Si queremos hacia el futuro una sociedad más justa, una mayor moralidad en el manejo del país, tanto a nivel público como privado, será necesario trascender la moral calvinista de nuestras instituciones, mediante una acción responsable de las instancias educativas en la formación política de la juventud. 
SUMARIO,- El texto recoge la intervención oral del autor en el Ciclo de Conferencias "Sobre el porvenir de nuestras escuelas". En él plantea la necesidad de pensar los fines de la educación como parte fundamental de una política en materia educativa. Los fines de la Escuela deben estar enmarcados dentro de un determinado proyecto social y un determinado estilo de desarrollo, La escuela debe aprender a aprender, aprender a hacer y aprender a ser, al tener como fin la educación para la libertad y para la eticidad.

DESCRIPTORES - Filosofía de la educación - Fines de la educación - Política educacional. 